FACTA UNIVERSITATIS

Series: Mechanical Engineering Vol. 15, No 3, 2017, pp. 439 - 456

https://doi.org/10.22190/FUME170508024C

Original scientific paper

\title{
A NOVEL HYBRID METHOD FOR NON-TRADITIONAL MACHINING PROCESS SELECTION USING FACTOR RELATIONSHIP AND MULTI-ATTRIBUTIVE BORDER APPROXIMATION METHOD
}

\author{
UDC 658.5
}

\author{
Prasenjit Chatterjee $^{1}$, Supraksh Mondal ${ }^{2}$, Soumava Boral ${ }^{3}$, \\ Arnab Banerjee ${ }^{1}$, Shankar Chakraborty ${ }^{4}$ \\ ${ }^{1}$ Department of Mechanical Engineering, MCKV Institute of Engineering, India \\ ${ }^{2}$ Department of Mechanical Engineering, Mallabhum Institute of Technology, India \\ ${ }^{3}$ Subir Chodhury School of Quality and Reliability, Indian Institute of Technology, \\ Kharagpur, India \\ ${ }^{4}$ Department of Production Engineering, Jadavpur University, India
}

\begin{abstract}
Selection of the most appropriate non-traditional machining process (NTMP) for a definite machining requirement can be observed as a multi-criteria decision-making (MCDM) problem with conflicting criteria. This paper proposes a novel hybrid method encompassing factor relationship (FARE) and multi-attributive border approximation area comparison (MABAC) methods for selection and evaluation of NTMPs. The application of FARE method is pioneered in NTMP assessment domain to estimate criteria weights. It significantly condenses the problem of pairwise comparisons for estimating criteria weights in MCDM environment. In order to analyze and rank different NTMPs in accordance with their performance and technical properties, MABAC method is applied. Computational procedure of FARE-MABAC hybrid model is demonstrated while solving an NTMP selection problem for drilling cylindrical through holes on non-conductive ceramic materials. The results achieved by FARE-MABAC method exactly corroborate with those obtained by the past researchers which validate the usefulness of this method while solving complex NTMP selection problems.
\end{abstract}

Key Words: Non-traditional Machining Processes, MCDM, Factor Relationship, MABAC

Received May 08, 2017 / Accepted November 08, 2017

Corresponding author: Prasenjit Chatterjee

Affiliation: Department of Mechanical Engineering, MCKV Institute of Engineering, Howrah- 711204, India

E-mail: prasenjit2007@gmail.com 


\section{INTRODUCTION}

Increasing global competition and rapid progress in manufacturing expertise are the major state of things in today's commercial environment. They have forced the manufacturing organizations to reallocate the business priorities in the direction of quality, cost optimization and responsiveness to market changes. The manufacturing scenario of the $21^{\text {st }}$ century is budding out as the integration of fragmented consumer market and rapidly varying production technologies. These changes are motivating the manufacturing organizations to struggle along several product dimensions including design, manufacturing and others. Although manufacturing has never been utilized as a viable weapon historically, still, the market place of the $21^{\text {st }}$ century demands manufacturing technologies to presume an imperative role in the new competitive arena. At present, customers aspire for a huge variety of products. The growing need for generating and machining complex and precise shapes in newer materials, like glass, titanium, ceramics, high strength temperature resistant (HSTR) alloys, fiber-reinforced composites, stainless steel, refractory materials and other difficult-to-machine alloys in nonexistence of adequately hard and strong cutting tool materials has resulted in the advancements of a number of new machining processes, commonly known as non-traditional machining processes (NTMPs). Now-a-days, NTM is considered as one of the major strategic resources for operational enhancement and for maintaining competitive position of an organization in the global marketplace. This competitive environment has refurbished interest with respect to research on economic analysis and NTMP validation methods, which can be utilized to aid organizations in selecting suitable NTMPs to meet their operational and business objectives. The conventional machining processes mostly remove materials in the form of chips by applying forces on the work material with a wedge-shaped cutting tool that is harder than the work material. These forces stimulate plastic deformation in the workpiece which leads to shear deformation next to the shear plane and also lay the foundation for chip formation. As compared to the conventional machining processes, the NTMPs use variety of mechanical, thermoelectrical, electrochemical and chemical energies to provide machining or removing materials in the shape of chips or atoms to get the preferred accuracy and burr-free machined surface [1,2]. Material removal perhaps occurs by means of chip formation or without chip formation. For example, in abrasive jet machining (AJM), chips are in infinitesimal dimension and for electrochemical machining (ECM), material removal takes place because of electrochemical dissolution at atomic level. Thus, an exhaustive knowledge about various machining characteristics is very important for efficient exploitation of the capabilities of different NTMPs. Comparing to the conventional machining processes, NTMPs possess superior process capabilities whose application domain may go on increasing in diverse ranges. As NTMPs can provide new ways of satisfying the demands of modern technological advances in many areas, including data transmission and miniaturization, the designers and nowadays manufacturing engineers are venturing towards the applications of different NTMPs to fulfill the machining and surface quality requirements. Latest possibility of choices from a group of available NTMPs has been unlocked for designing and machining extremely intricate products. Existence of a huge number of NTMPs along with multifarious uniqueness and capabilities, and lack of proficiency in NTMP selection domain have 
forced the manufacturing and design engineers to develop structured approaches for NTMP selection for assorted machining applications. The uncertainties regarding material requirements, shape applications, technical capabilities and other process attributes with the availability of many alternatives make NTMP selection for a meticulous application a very difficult and risky task. To properly select the predominant NTMP for a specific application, the process engineer must understand the limitations as well as strengths of each NTMP with specific functionalities and applicability [3].

\section{REVIEW OF LITERATURE ON NTMP SELECTION}

To the utmost level of information, there are not so many published works on selection of NTMPs in multi-criteria decision-making (MCDM) environment. Before probing for an appropriate NTMP, it is obligatory to be acquainted with the nature of application where the NTMP would be implemented. Even though an NTMP can be employed very efficiently for a particular application, changes in the application type, material and other requirements can reduce its efficiency significantly. Therefore, the selection approach must start with a clear identification of the application domain. Cogun [3,4] developed a computer-aided NTMP selection approach for some given industrial applications using an interactively generated 16-digit classification code. The developed system was used to categorize and rank the viable NTMPs. Yurdakul and Cogun [5] proposed a combined analytical hierarchy process (AHP) and technique for order preference by similarity to ideal solution (TOPSIS)-based procedure for selecting suitable NTMPs for the given industrial application viewpoints and characterized the alternative NTMPs using a number of criteria, including workpiece material suitability, shape applications, process capability and cost considerations. Chakraborty and Dey [6] developed an AHP-based expert system to help the decision maker (DM) for selecting the most appropriate NTMPs for some given applications. The expert system was based on the priority assessments for different criteria and sub-criteria as associated to the explicit NTMP selection problems. Chakraborty and Dey [7] designed a quality function deployment (QFD)-based expert system for NTMP selection, considering various product and process characteristics. The weights of NTMP selection criteria were used to calculate overall scores for the possible NTMPs. Das Chakladar and Chakraborty [8] utilized a combined AHP-TOPSIS-based methodology for selection of the best NTMPs for some given machining applications. Edison Chandrasselan et al. [9] proposed a web-based knowledge base system for identifying the most appropriate NTMP, while considering material requirements, shape applications, process economy and process capabilities parameters. Edison Chandrasselan et al. [10] illustrated a knowledge-based system for recognizing the most suitable NTMP from 20 alternatives of engineering significance. The developed knowledge-based system considered material variety and some process capability constraints, including tolerance, corner radii, surface damage, taper, width of cut, surface finish, hole diameter, depth-to-diameter ratio (for cylindrical holes) and depth-towidth ratio (for blind cavities) to select the best NTMP for a particular machining application. Das Chakladar et al. [11] applied a digraph-based decision-making approach to select the most appropriate NTMPs for some real time manufacturing applications. Sadhu 
and Chakraborty [12] applied a two-phase decision-making model, based on data envelopment analysis (DEA) and weighted overall efficiency ranking method, to select and rank feasible NTMPs for some certain shape characteristics and work material combinations. Das and Chakraborty [13] developed an analytic network process (ANP)-based graphical user interface model to select the most appropriate NTMPs, captivating interdependency and feedback relationships among different criteria, affecting the NTMP selection decision. Chakraborty [14] applied multi-objective optimization by ratio analysis (MOORA) method to choose NTMPs for various engineering applications. Temuçin et al. [15] provided some methodical approaches and a decision support model in fuzzy and crisp situations to deal with NTMP selection problems. Karande and Chakraborty [16] applied an integrated preference ranking organization method for enrichment evaluation (PROMETHEE) as well as a geometrical analysis for an interactive aid (GAIA) method for solving NTMP selection problems. The suggested approach would act as a visual decision support to the process engineers. Temucin et al. [17] proposed a fuzzy decision support system for selecting NTMPs considering the vagueness of several inter-related decision criteria. Choudhury et al. [18] developed a TOPSIS-AHP based expert system for NTMP selection and considered several paradoxical criteria. Prasad and Chakraborty [19] developed a quality function deployment (QFD) based expert system module in Visual Basic 6.0 to automate the NTMP selection. Temuçin et al. [20] proposed a fuzzy decision model for NTMPs selection. A graphical user interface (GUI), built in SETED 1.0 software, was also developed to validate the potentiality of the proposed approach. Roy et al. [21] suggested a fuzzy AHP and QFD technique for the purpose of NTMP selection. Madic et al. [22] again explored the applicability of MOORA and AHP methods while solving NTMP selection problems and compared the results with TOPSIS method. Khandekar and Chakraborty [23] proposed the application of fuzzy axiomatic design (AD) principles to select best NTMP for generating cavities on ceramics and micro-holes on hardened tool steel and titanium materials, based on their practical/industrial importance. Boral \& Chakraborty [24] applied case-based reasoning (CBR) approach for NTMPs selection using a GUI, developed in Visual Basic 6.0. Roy et al. [25] proposed a novel approach combining fuzzy AHP with QFD for NTMPs selection and ranked the alternatives by applying grey relational analysis (GRA) methodology.

Regarding the above survey of referential literature, it has been observed that in most of the NTMP selection papers, the past researchers have mainly applied AHP, TOPSIS, QFD and DEA models. Very few applications are related to PROMETHEE, MOORA and EVAMIX etc. methods. AHP is an expedient method of breaking down an intricate and unstructured problem into its various constituent parts to amalgamate the judgments in order to establish the highest priority variables which may influence the outcome of the situation. However, the computational requirement of AHP is tremendous even for a small problem. It suffers from inconsistencies between judgment and ranking criteria. Rank reversal may occur due to the changes of the order of the alternatives when a new alternative is added to the problem. When the number of the levels in the hierarchy increases, the number of pairwise comparisons also increases which is a very time consuming effort [26]. The fundamental theory of the TOPSIS method is based on the concept that the best alternative has the shortest distance from the ideal solution and the farthest distance from the negative-ideal solution. The TOPSIS method instigates two reference points using 
vector normalization; however, it does not contemplate the relative significance of the distances from these reference points. It means that the best alternative in the TOPSIS method may not always mean that it is the closest to the ideal solution [27]. As a typical formulation of DEA builds a separate linear program for every alternative, so it becomes computationally intensive. Also as DEA is an extreme point method, measurement error can root considerable problems. DEA does not provide estimates which can effortlessly be validated with conventional statistical procedures and it does not tender the ranking of the alternatives [28, 29]. A major objective of QFD is to transform customer requirements (CRs) into engineering characteristics (ECs) of a product. QFD is a very time consuming approach. Numerous complexities may be countered while prioritizing CRs and EC using ordinal ratings. Differentiating between diverse and contradictory CRs is very difficult [30,31]. PROMETHEE method does not provide the possibility to really structure a decision problem. In the case of many criteria and alternatives, it may become difficult for the DM to obtain a clear view of the problem and to evaluate the results due to the involvement of different preferential parameters like preference functions which may be very difficult to define in real time scenarios [32].

The literature survey also indicates that criteria weights for NTMP selection problems are generally determined by expert opinion-based pair-wise comparisons using AHP method. The criteria weights being one of the vital decisive phases in the selection process, the accuracy of expert evaluation essentially depends on the number of criteria. When this number is too large, an expert may no longer be proficient to evaluate the criteria to determine their relative importance.

Thus, it is evident that the past researchers have adopted different decision-making tools for evaluating, justifying and selecting NTMPs, but all those methods are either very complicated or require lengthy computations and sometimes need the help of linear programming tools to solve the developed models. Also, for the decision-making problems with large number of criteria and smaller number of alternatives, those approaches may occasionally give poor results. To overcome such difficulties, the present paper proposes a novel hybrid method encompassing a new criteria weighting technique, namely factor relationship (FARE) and multi-attributive border approximation area comparison (MABAC) approaches, as shown in Fig. 1. The proposed model allows criteria weight calculation based on the relationship between one criterion with the others to reduce the amount of expert assessment, while the precision of evaluation augments and also provides a more precise and accurate rankings of the feasible NTMP alternatives. 


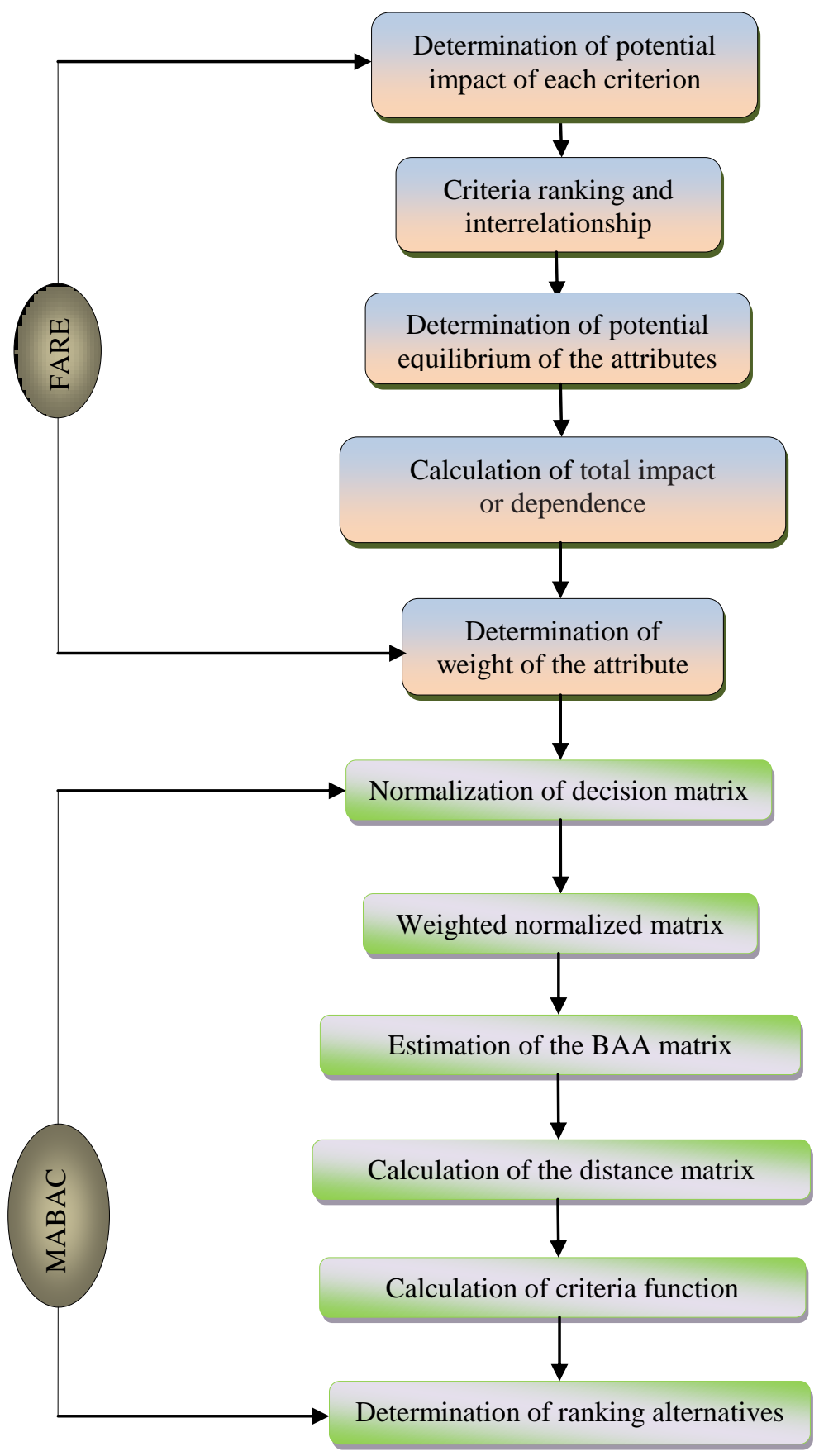

Fig. 1 Proposed FARE-MABAC hybrid method 


\section{METHODS}

\subsection{FARE method}

Ginevicius [33] developed FARE method for estimating criteria weights in MCDM background. The procedural steps to apply FARE method to determine criteria weights are described as follows [33-35]:

Step 1: Determination of potential impact of the attributes:

Initially, the potential impact of the criteria is found out using:

$$
P=S(n-1)
$$

where $P$ is the potential of the system's criteria impact and $S$ is the maximum value of the evaluation scale used, as given in Table1.

Step 2: Ranking criteria and assessment of their interrelationship:

Criteria are now ranked based on their importance while the relationship among the criteria is assessed using Table 2. Any criterion with a lower rank has less significant impact on other criteria having higher ranks and consequently it ought to transmit a larger part of its potential impact to others.

Table 1 Scale of quantitative evaluation of interrelationship between the system's attributes

\begin{tabular}{lc}
\hline Type of the effect produced & $\begin{array}{c}\text { Rating of the effect produced } \\
\text { by interrelationship (in points) }\end{array}$ \\
\hline Almost none & 1 \\
Very weak & 2 \\
Weak & 3 \\
Lower than average & 4 \\
Average & 5 \\
Higher than average & 6 \\
Strong & 7 \\
Very strong & 8 \\
Almost absolute & 9 \\
Absolute & 10 \\
\hline
\end{tabular}

Table 2 Measurement scale for pair wise comparison

\begin{tabular}{lc}
\hline Verbal judgment or preference & Numerical rating \\
\hline Extremely preferred & 9 \\
Very strongly to extremely preferred & 8 \\
Very strongly preferred & 7 \\
Strongly to very strongly preferred & 6 \\
Strongly preferred & 5 \\
Moderately to strongly preferred & 4 \\
Moderately preferred & 3 \\
Equally to moderately preferred & 2 \\
Equally preferred & 1 \\
\hline
\end{tabular}


Step 3: Determination of impact of the attributes on the main attribute:

The impact of criterion $a_{j}$ on the main criterion is computed and then, this impact is transformed as follows:

$$
a_{1 j}=S-\tilde{a}_{1 j}
$$

where, $a_{1 j}$ is the impact of the $j^{\text {th }}$ criterion on the first main criterion and $\tilde{a}_{1 j}$ is the part of the $j^{\text {th }}$ attribute's potential impact transmitted to the main criterion.

Step 4: Determination of total impact:

The total impact and consistency of any criterion is calculated using Eq. (3). The subset considered is reliable, consistent and steady if the total impact of its criteria with a positive sign is equal to the total impact with a negative sign, i.e. their sum is always equal to zero.

$$
P_{j}=\sum_{j=1}^{n} a_{i j}, j \neq i
$$

The total impact can also be estimated using Eq. (4). The total impact or dependence of a criterion exemplifies its dominance over the others. Therefore, the most significant criterion in the matrix presented should be the first one with maximum total dominance.

$$
P_{j}=P_{1}-n \cdot a_{1 j}
$$

where $P_{j}$ is the total impact (dependence) of the $j^{\text {th }}$ criterion and $n$ is the total number of criteria.

Step 5: Computation of attribute weights:

Lastly, the criteria weights are derived using:

$$
w_{j}=\frac{P_{j}^{f}}{P_{S}}=\frac{P_{1}-n a_{1 j}+S(n-1)}{n S(n-1)}
$$

where $P_{S}$ is the total potential of a set of criteria, calculated using Eq. (6) and $P_{j}^{f}$ is the actual total impact of the $j^{\text {th }}$ criterion of the system, calculated using Eq. (7):

$$
\begin{gathered}
P_{S}=n \cdot P=n \cdot S(n-1) \\
P_{j}^{f}=P_{1}-n a_{1 j}+S(n-1)=P_{j}+P
\end{gathered}
$$

where $P_{j}$ is the total impact produced by the $j^{\text {th }}$ criterion of the system signifying its total dependence on the other criteria and $P$ is the potential impact of the criteria.

\subsection{MABAC method}

The MABAC method was developed at the research centre of University of Defense in Belgrade. Once the weight importances of the criteria are assessed using FARE method, the provisions are all laid to instigate the mathematical formulation of MABAC method. The elementary concept of this method can be realized in the explanation of the 
distance of criterion function of each alternative from the border approximation area. In this section, six easy steps to execute MABAC method are presented as follows [36-39]:

Step 1: Formation of the preliminary decision matrix $(X)$ :

The primary step is to assess $m$ alternatives according to a set of $n$ predefined criteria, describing the alternatives. This decision matrix is presented in the formation of vectors $A_{i}=\left(x_{i 1}, x_{i 2}, \ldots, x_{i n}\right)$, where $x_{i j}$ is the value of the $i^{\text {th }}$ alternative according to the $j^{\text {th }}$ criterion $(i=1,2, \ldots, m ; j=1,2, \ldots, n)$.

$$
X=\begin{gathered}
A_{1} \\
A_{2} \\
\ldots \\
A_{m}
\end{gathered}\left[\begin{array}{cccc}
x_{11} & x_{12} & \ldots & x_{1 n} \\
x_{21} & x_{22} & \ldots & x_{2 n} \\
\ldots & \ldots & \ldots & \ldots \\
x_{m 1} & x_{m 2} & \ldots & x_{m n}
\end{array}\right]
$$

Step 2: Normalization of initial decision matrix $(X)$ :

Normalize the initial decision matrix $(X)$ using linear normalization method. The reason of normalization is to attain dimensionless assessments of different criteria to make them comparable with each other.

$$
R=\begin{gathered}
A_{1} \\
A_{2} \\
\ldots \\
A_{m}
\end{gathered}\left[\begin{array}{cccc}
r_{11} & r_{12} & \ldots & r_{1 n} \\
r_{21} & r_{22} & \ldots & r_{2 n} \\
\ldots & \ldots & \ldots & \ldots \\
r_{m 1} & r_{m 2} & \ldots & r_{m n}
\end{array}\right]
$$

The components of the normalized decision matrix $(R)$ are determined using the following equations:

a) For beneficial criteria (for which higher values are always desirable)

$$
r_{i j}=\frac{x_{i j}-x_{j}^{-}}{x_{j}^{+}-x_{j}^{-}}
$$

b) For non-beneficial or cost criteria (for which lower values are always preferable)

$$
r_{i j}=\frac{x_{i j}-x_{j}^{+}}{x_{j}^{-}-x_{j}^{+}}
$$

where $x_{j}^{+}$and $x_{j}^{-}$are the maximum and minimum values of $j^{\text {th }}$ criterion according to the alternatives.

Step 3: Determination of the weighted normalized decision matrix $(V)$ :

The elements from the weighted matrix $(V)$ are calculated according to

$$
v_{i j}=w_{j} \cdot\left(r_{i j}+1\right)
$$

where $r_{i j}$ are the elements of the normalized matrix $(R), w_{j}$ are the weight coefficients of the criteria. 


$$
V=\left[\begin{array}{cccc}
v_{11} & v_{12} & \ldots & v_{1 n} \\
v_{21} & v_{22} & \ldots & v_{2 n} \\
\ldots & \ldots & \ldots & \ldots \\
v_{m 1} & v_{m 2} & \ldots & v_{m n}
\end{array}\right]=\left[\begin{array}{cccc}
w_{1} \cdot\left(r_{11}+1\right) & w_{2} \cdot\left(r_{12}+1\right) & \ldots & w_{n} \cdot\left(r_{1 n}+1\right) \\
w_{1} \cdot\left(r_{21}+1\right) & w_{2} \cdot\left(r_{22}+1\right) & \ldots & w_{n} \cdot\left(r_{2 n}+1\right) \\
\ldots & \ldots & \ldots & \ldots \\
w_{1} \cdot\left(r_{m 1}+1\right) & w_{2} \cdot\left(r_{m 2}+1\right) & \ldots & w_{n} \cdot\left(r_{m n}+1\right)
\end{array}\right]
$$

where $n$ is the total number of criteria, $m$ is the total number of alternatives.

Step 4: Estimation of the border approximation area (BAA) matrix (B):

The elements of matrix $(B)$ for each criterion are determined according to:

$$
b_{j}=\left(\prod_{i=1}^{m} v_{i j}\right)^{1 / m}
$$

where $v_{i j}$ are the elements of weighted matrix $(V)$, and $m$ is the total number of alternatives.

After calculating value $g_{j}$ for each criterion, a border approximation area matrix $(B)$ is formed with format $n \times 1$.

$$
\begin{aligned}
& \begin{array}{llll}
c_{1} & c_{2} & \ldots & c_{3}
\end{array} \\
& B=\left[\begin{array}{llll}
b_{1} & b_{2} & \ldots & b_{n}
\end{array}\right]
\end{aligned}
$$

Step 5: Calculation of the distance matrix of alternatives $(Q)$ from the BAA:

$$
Q=\left[\begin{array}{cccc}
q_{11} & q_{12} & \ldots & q_{1 n} \\
q_{21} & q_{22} & \ldots & q_{2 n} \\
\ldots & \ldots & \ldots & \ldots \\
q_{m 1} & q_{m 2} & \ldots & q_{m n}
\end{array}\right]
$$

The distance of the alternatives from the BAA is determined as the difference between the elements in weighted matrix $(V)$ and the value of border approximation area $(B)$ :

$$
\begin{gathered}
Q=V-B=\left[\begin{array}{cccc}
v_{11} & v_{12} & \ldots & v_{1 n} \\
v_{21} & v_{22} & \ldots & v_{2 n} \\
\ldots & \ldots & \ldots & \ldots \\
v_{m 1} & v_{m 2} & \ldots & v_{m n}
\end{array}\right]-\left[\begin{array}{cccc}
b_{1} & b_{2} & \ldots & b_{n} \\
b_{1} & b_{2} & \ldots & b_{n} \\
\ldots & \ldots & \ldots & \ldots \\
b_{1} & b_{2} & \ldots & b_{n}
\end{array}\right] \\
Q=\left[\begin{array}{cccc}
v_{11}-b_{1} & v_{12}-b_{2} & \ldots & v_{1 n}-b_{n} \\
v_{21}-b_{1} & v_{22}-b_{2} & \ldots & v_{2 n}-b_{n} \\
\ldots & \ldots & \ldots & \ldots \\
v_{m 1}-b_{1} & v_{m 2}-b_{2} & \ldots & v_{m n}-b_{n}
\end{array}\right]=\left[\begin{array}{cccc}
q_{11} & q_{12} & \ldots & q_{1 n} \\
q_{21} & q_{22} & \ldots & q_{2 n} \\
\ldots & \ldots & \ldots & \ldots \\
q_{m 1} & q_{m 2} & \ldots & q_{m n}
\end{array}\right]
\end{gathered}
$$

where $b_{j}$ is the BAA for $j^{\text {th }}$ criterion and $v_{i j}$ is the weighted matrix of elements $(V), n$ is the number of criteria, $m$ is the number of alternatives. 
Alternative $A_{i}$ may belong to BAA $(B)$, upper approximation area $\left(B^{+}\right)$or lower approximation area $\left(B^{-}\right)$, i.e. $A_{i} \in\left\{B \vee B^{+} \vee B^{-}\right\}$. Upper approximation area $\left(B^{+}\right)$is the area which contains ideal alternative $\left(A^{+}\right)$, while lower approximation area $\left(B^{-}\right)$is the area which contains anti-ideal alternative $\left(A^{-}\right)$, as shown in Fig. 2.

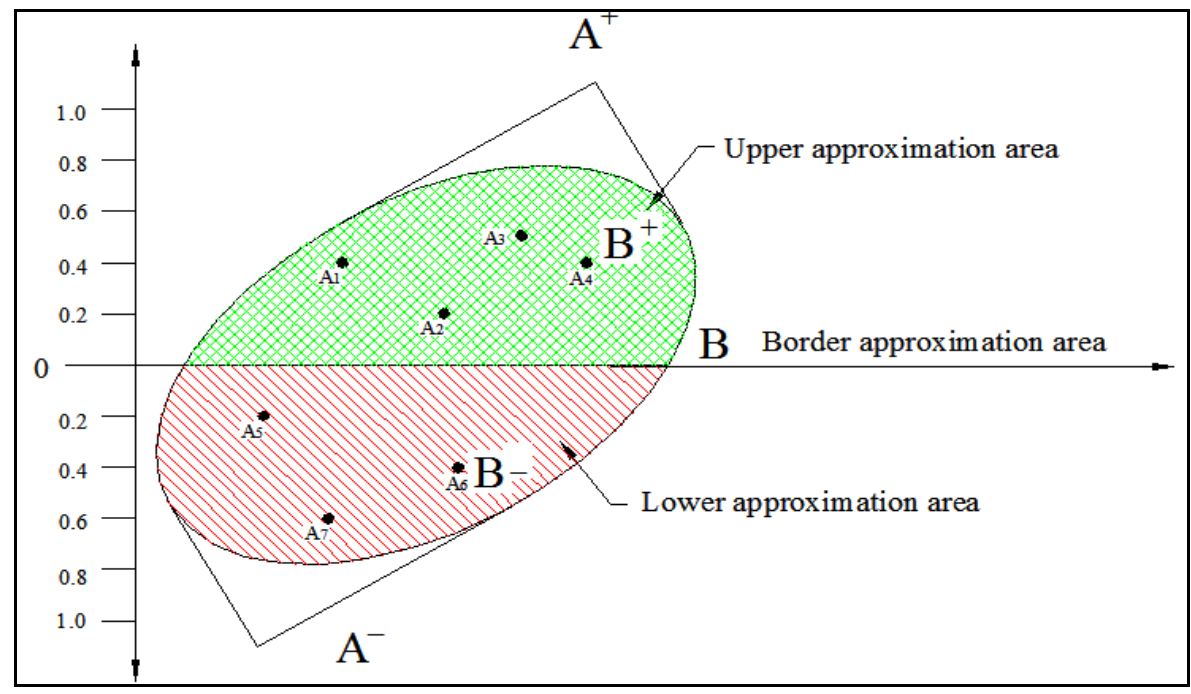

Fig. 2 Presentation of the upper $\left(B^{+}\right)$, lower $\left(B^{-}\right)$and border $(B)$ approximation areas [36]

The belonging of alternative $A_{i}$ to approximation area $\left(B, B^{+}\right.$or $\left.B^{-}\right)$is determined on the basis of Eq. (18):

$$
A_{i} \in\left\{\begin{aligned}
B^{+} & \text {if } q_{i j}>0 \\
B & \text { if } q_{i j}=0 \\
B^{-} & \text {if } q_{i j}<0
\end{aligned}\right.
$$

In order to select alternative $A_{i}$ as the best in the set, it is necessary for it to belong to upper approximate area $\left(B^{+}\right)$for as many criteria as possible. If value $q_{i j}>0$, that is $q_{i j} \in B^{+}$, then alternative $A_{i}$ is near or equal to the ideal alternative. If value $q_{i j}<0$, that is $q_{i j} \in B^{-}$, it indicates that alternative $A_{i}$ is near or equal to the anti-ideal alternative.

Step 6: Calculation of criteria function $\left(S_{i}\right)$ values and ranking the alternatives:

Calculation of the criteria function values for the alternatives is obtained as the sum of the distance of the alternative from the border approximation area $\left(q_{i}\right)$, as indicated by Eq. (19). By adding together the rows of elements of matrix $Q$, the final values of the criterion functions for the alternatives can be obtained. Finally, alternatives are arranged in the descending order of $S_{i}$ values and the alternative with the highest $S_{i}$ value is ranked as the best one:

$$
S_{i}=\sum_{j=1}^{n} q_{i j}, j=1,2, \ldots, n, i=1,2, \ldots, m
$$




\section{ILLUSTRATIVE EXAMPLE}

To reveal the computational flexibility and expediency of the proposed hybrid FAREMABAC method, an NTMP selection problem for drilling cylindrical through holes on nonconductive ceramic materials is considered here. The diameter (D) and slenderness ratio $(\mathrm{L} / \mathrm{D})$ of the hole are given as $0.64 \mathrm{~mm}$ and 5.7 respectively, where $\mathrm{L}$ designates hole depth. Yurdakul and Cogun [5] developed an MCDM approach for deciding appropriate NTMPs for different industrial applications. The authors characterized different NTMPs using a number of attributes, including shape applications, workpiece material suitability, process capability and cost considerations to provide a way of evaluating the levels of achievement of NTMPs with respect to their capabilities and output quality. In the manufacturing domain, NTMPs are used generally for machining different shapes, including blind cavities, producing through profiles or holes, cutting operations and surface finishing operations. Work material suitability mainly indicates the easiness of an NTMP to machine a particular material. Based on the shape application and workpiece material suitability constraints, Yurdakul and Cogun [5] eradicated a number of NTMPs, including ECM, ECG, ECH, EDM, WEDM, PAC and WJM from further deliberations for this cylindrical through hole drilling operation. Yurdakul and Cogun [5] observed AJM, USM, CHM, EBM and LBM processes as the most feasible alternatives to be judged and developed the corresponding decision matrix, as shown in Table 3. Tolerance (TL), surface finish (SF), surface damage $(\mathrm{SD})$, taper $(\mathrm{T})$, material removal rate (MRR), work material (M) and cost (C) were chosen as the most pertinent attributes, affecting this NTM process selection decision. TL and SF are the two most important product capability attributes, used to measure the performance of an NTMP for a particular machining application. Tolerance can be defined as the difference between the maximum and minimum dimensions of a component. Depending on the type of application, the permissible variation of dimension is set according to the available standard grades. It also relates to the capability of an NTMP stating how closely the process can achieve the required surface finish on the given work material. Material removal rate is one of the most important criteria leading to the fact that higher MRR leads to lower machining time. The effectiveness of an NTMP is usually measured in terms of its MRR. Machining cost is an important criterion for NTMP selection. It generally comprises tooling and fixture, power consumption and tool wear costs. Tooling and fixture costs include workpiece holding and adjustment costs. Power consumption includes costs associated with electricity used for material removal or in driving pumps, compressors, motors, heating units, beam generators, cost of electrolytes, dielectrics, chemicals, acid solutions or gases consumed during the machining operation. Tool wear cost includes entire tool and tool replacement costs. Yurdakul and Cogun [5] developed a generalized overall machining cost formula to provide an approximated cost score for NTMPs, based on tooling and fixture, power consumption and tool wear cost elements. Among these seven considered criteria, TL (mm), SF (CLA) $(\mu \mathrm{m}), \mathrm{SD}(\mu \mathrm{m}), \mathrm{T}(\mathrm{mm} / \mathrm{mm})$ and C are non-beneficial in nature, whereas, MRR $\left(\mathrm{mm}^{3} / \mathrm{mm}\right)$ and $\mathrm{M}$ are beneficial. Also, among these attributes, TL, SF, SD, T and MRR are expressed quantitatively, having absolute numerical values, whereas $\mathrm{M}$ and $\mathrm{C}$ have qualitative measures for which ranked value judgments on some qualitative scales are used, as shown in Tables 4-6 [5]. Table 7 shows the transformed decision matrix for this NTMP selection problem. The criteria weights were determined by Yurdakul and Cogun [5] as $\mathrm{w}_{\mathrm{TL}}$ $=0.32, \mathrm{w}_{\mathrm{SF}}=0.19, \mathrm{w}_{\mathrm{SD}}=0.04, \mathrm{w}_{\mathrm{T}}=0.04, \mathrm{w}_{\mathrm{MRR}}=0.19, \mathrm{w}_{\mathrm{M}}=0.11$ and $\mathrm{w}_{\mathrm{C}}=0.11$ using AHP 
method. Yurdakul and Cogun [5] solved this NTMP selection problem using a combined AHP-TOPSIS method and observed the ranking of the alternative NTM processes as USM $>\mathrm{LBM}>\mathrm{EBM}>\mathrm{CHM}>\mathrm{AJM}$. Now, this NTMP problem is solved using the proposed FARE-MABAC method and the results are then compared.

Table 3 NTMP selection matrix for drilling cylindrical through holes on ceramics [5]

\begin{tabular}{lllrrrrr}
\hline NTM process & \multicolumn{1}{c}{ TL } & SF & \multicolumn{1}{c}{ SD } & \multicolumn{1}{c}{ T } & MRR & M & C \\
\hline AJM $\left(\mathrm{A}_{1}\right)$ & 0.05 & 0.6 & 2.5 & 0.005 & 50 & Good & 4 \\
USM $\left(\mathrm{A}_{2}\right)$ & 0.013 & 0.5 & 25 & 0.005 & 500 & Good & 5 \\
CHM $\left(\mathrm{A}_{3}\right)$ & 0.03 & 2 & 5 & 0.3 & 40 & Poor & 2 \\
EBM $\left(\mathrm{A}_{4}\right)$ & 0.02 & 3 & 100 & 0.02 & 2 & Good & 1 \\
LBM $\left(\mathrm{A}_{5}\right)$ & 0.02 & 1 & 100 & 0.05 & 2 & Good & 1 \\
\hline
\end{tabular}

Table 4 Qualitative scale for workpiece material suitability level [5]

\begin{tabular}{lccc}
\hline Linguistic variable & Poor & Fair & Good \\
\hline Scale value & 1 & 2 & 3 \\
\hline
\end{tabular}

\subsection{Calculation of criteria weights using FARE method}

In this phase, the calculation of criteria weights are performed using the steps as explained in Section 3.2. First of all, the potential impact of the attributes is computed as 60 . Next the initial priority of the NTMP selection criteria (TL $>\mathrm{SF}>\mathrm{MRR}>\mathrm{M}>\mathrm{C}>\mathrm{SD}>\mathrm{T}$ ) are decided according to their weight values as determined by Yurdakul and Cogun [5] and an extensive literature review as presented earlier. The priority order indicates that TL is the most preferred criterion, while $\mathrm{T}$ is the least important criterion for the considered NTMP selection problem. Since TL is the most significant criterion, the impact of other criteria will be transferred through it and, therefore, their direct impact on this NTMP selection problem will be decreased, as exhibited through Table 8. As shown in this table, the matrix of potential equilibrium has a particular structure, i.e. $a_{i j}=-a_{j i}$. For example, priority of PL to SF is 3, then priority of SF to PL is automatically settled as -3 . In this case, a row or column of the matrix demonstrates the total (summed up) effect or dependence of a particular criterion on other criteria compared with it.

Table 5 Cost levels of different NTMPs [5]

\begin{tabular}{lcccc}
\hline NTMP & $\begin{array}{c}\text { Tooling and } \\
\text { fixture cost rating }\end{array}$ & $\begin{array}{c}\text { Power consumption } \\
\text { rating }\end{array}$ & $\begin{array}{c}\text { Tool wear } \\
\text { cost rating }\end{array}$ & $\begin{array}{c}\text { Overall machining } \\
\text { cost score }\end{array}$ \\
\hline $\mathrm{A}_{1}$ & Low (3) & Low (3) & Medium (5) & 4 \\
$\mathrm{~A}_{2}$ & Low (3) & Low (3) & High (7) & 5 \\
$\mathrm{~A}_{3}$ & Low (3) & Very low (1) & Very low (1) & $1.8(2)$ \\
$\mathrm{A}_{4}$ & Very low (1) & Low (3) & Very low (1) & $1.2(1)$ \\
$\mathrm{A}_{5}$ & Very low (1) & Very low (1) & Very low (1) & $1.2(1)$ \\
\hline
\end{tabular}


Table 6 Qualitative scale used to gauge machining cost elements [5]

\begin{tabular}{lccccccccc}
\hline Linguistic variable & Very low & Low & & Medium & High & Very high \\
\hline Scale value & 1 & 2 & 4 & 3 & 5 & 6 & 7 & 8 & 9 \\
\hline
\end{tabular}

Table 7 Transformed decision matrix

\begin{tabular}{cllrlrrr}
\hline NTMP & TL & SF & \multicolumn{1}{c}{ SD } & \multicolumn{1}{c}{ T } & MRR & M & C \\
\hline $\mathrm{A}_{1}$ & 0.05 & 0.6 & 2.5 & 0.005 & 50 & 3 & 4 \\
$\mathrm{~A}_{2}$ & 0.013 & 0.5 & 25 & 0.005 & 500 & 3 & 5 \\
$\mathrm{~A}_{3}$ & 0.03 & 2 & 5 & 0.3 & 40 & 1 & 2 \\
$\mathrm{~A}_{4}$ & 0.02 & 3 & 100 & 0.02 & 2 & 3 & 1 \\
$\mathrm{~A}_{5}$ & 0.02 & 1 & 100 & 0.05 & 2 & 3 & 1 \\
\hline
\end{tabular}

Table 8 Summary matrix of potential equilibrium of the NTMP selection criteria

\begin{tabular}{ccccccccc}
\hline Criteria & TL & SF & SD & T & MRR & M & C & $\begin{array}{c}\text { Total effect } \\
\text { (dependence) }\end{array}$ \\
\hline TL & & 3 & 3 & 4 & 4 & 3 & 5 & 22 \\
SF & -3 & & 2 & 3 & 3 & 4 & 4 & 13 \\
SD & -3 & -2 & & 2 & -4 & -3 & -3 & -13 \\
T & -4 & -3 & -2 & & -2 & -2 & -2 & -15 \\
MRR & -4 & -3 & 4 & 2 & & 4 & 4 & 7 \\
M & -3 & -4 & 3 & 2 & -4 & & 4 & -2 \\
C & -5 & -4 & 3 & 2 & -4 & -4 & & -12 \\
\hline Total effect & -22 & -13 & 13 & 15 & -7 & 2 & 12 & \\
\hline
\end{tabular}

In order to calculate the total impact $\left(P_{j}\right)$, summation of each row is computed using and also exhibited in Table 8. This table reveals that the total impact of the criteria set with a positive sign is equal to the total impact with a negative sign. Consequently, the set is totally consistent. Total potential $\left(P_{S}\right)$ value of 420 , required for determining the weights, is now computed using Eq. (6). For this example, $n=7$ and $P=60$. Once the $P_{S}$ value is calculated, the individual potentials of all the considered NTMP selection criteria are determined and the criteria weights are estimated, as given in Table 10. These weights are subsequently used for MABAC-based analysis.

Table 9 Total impact of NTMP selection criteria

\begin{tabular}{ccccccccc}
\hline Criteria & TL & SF & SD & T & MRR & M & C & Sum \\
\hline TL & & 7 & 7 & 6 & 6 & 7 & 5 & 38 \\
SF & -7 & & 8 & 7 & 7 & 6 & 6 & 27 \\
SD & -7 & -8 & & 8 & -6 & -7 & -7 & -27 \\
T & -6 & -7 & 8 & & -8 & -8 & -8 & -29 \\
MRR & -6 & -7 & 6 & 8 & & 6 & 6 & 13 \\
M & -7 & -6 & 7 & 8 & -6 & & 6 & 2 \\
C & -5 & -6 & 7 & 8 & -6 & -6 & & -8 \\
\hline
\end{tabular}


Table 10 Individual potential and criteria weight values

\begin{tabular}{cccc}
\hline Criteria & $P_{j}^{f}$ & $P_{S}=n . P=n . S(n-1)$ & $W_{j}=P_{j}^{f} / P_{S}$ \\
\hline TL & 98 & & $98 / 420=0.23$ \\
SF & 87 & & $87 / 420=0.21$ \\
SD & 33 & \multirow{2}{*}{$7 \times 60=420$} & $33 / 420=0.08$ \\
T & 31 & $31 / 420=0.07$ \\
MRR & 73 & & $73 / 420=0.17$ \\
M & 62 & $62 / 420=0.15$ \\
C & 52 & $52 / 420=0.12$ \\
\hline
\end{tabular}

\subsection{Application of MABAC method for selection of NTMPs}

Through the second phase, the evaluation and ranking of NTMP alternatives is now performed by applying the MABAC method. After forming the transformed decision matrix of Table 7, normalization of its elements is carried out respectively for beneficial and non-beneficial type criteria, as shown in Table 11.

Table 11 Normalized decision matrix for NTMP selection problem

\begin{tabular}{clllllll}
\hline NTMP & \multicolumn{1}{c}{ TL } & \multicolumn{1}{c}{ SF } & \multicolumn{1}{c}{ SD } & \multicolumn{1}{c}{ T } & \multicolumn{1}{c}{ MRR } & \multicolumn{1}{c}{ M } & \multicolumn{1}{c}{ C } \\
\hline $\mathrm{A}_{1}$ & 0 & 0.9600 & 1.0000 & 1.0000 & 0.2500 & 0.0964 & 1.0000 \\
$\mathrm{~A}_{2}$ & 1.0000 & 1.0000 & 0.7692 & 1.0000 & 0 & 1.0000 & 1.0000 \\
$\mathrm{~A}_{3}$ & 0.5405 & 0.4000 & 0.9744 & 0 & 0.7500 & 0.0763 & 0 \\
$\mathrm{~A}_{4}$ & 0.8108 & 0 & 0 & 0.9492 & 1.0000 & 0 & 1.0000 \\
$\mathrm{~A}_{5}$ & 0.8108 & 0.8000 & 0 & 0.8475 & 1.0000 & 0 & 1.0000 \\
\hline
\end{tabular}

Table 12 Weighted normalized matrix

\begin{tabular}{cccccccc}
\hline NTMP & TL & SF & SD & T & C & MRR & M \\
\hline $\mathrm{A}_{1}$ & 0.2333 & 0.4060 & 0.1571 & 0.1476 & 0.1500 & 0.1906 & 0.2952 \\
$\mathrm{~A}_{2}$ & 0.4667 & 0.4143 & 0.1390 & 0.1476 & 0.1200 & 0.3476 & 0.2952 \\
$\mathrm{~A}_{3}$ & 0.3595 & 0.2900 & 0.1551 & 0.0738 & 0.2100 & 0.1871 & 0.1476 \\
$\mathrm{~A}_{4}$ & 0.4225 & 0.2071 & 0.0786 & 0.1439 & 0.2400 & 0.1738 & 0.2952 \\
$\mathrm{~A}_{5}$ & 0.4225 & 0.3729 & 0.0786 & 0.1364 & 0.2400 & 0.1738 & 0.2952 \\
\hline
\end{tabular}

The elements of weighted normalized matrix $(V)$ are then estimated by multiplying the weight coefficients of the criteria with the elements of the normalized matrix using Eq. (12), as given in Table 11. For example, element $v_{12}$ of weighted matrix $(V)$ is obtained as follows:

$$
v_{12}=w_{2} x\left(r_{12}+1\right)=(0.96+1) \times 0.21=0.4060
$$

where $r_{I 2}$ is an element of normalized matrix $(R), w_{2}$ is the weight coefficient of criterion SF.

Now, border approximation area matrix $(B)$ is obtained by taking geometrical average of the values, as given in Table 13.

For example, BAA for criterion SF is obtained as follows:

$$
b_{2}=\left(\prod_{i=1}^{7} v_{i j}\right)^{1 / 7}=(0.4060 \times 0.4143 \times 0.2900 \times 0.2071 \times 0.3729)^{1 / 7}=0.3275
$$


Table 13 Border approximation area $(B)$ matrix

\begin{tabular}{cccccccc}
\hline BAA & TL & SF & SD & T & C & MRR & M \\
\hline$b_{j}$ & 0.3706 & 0.3275 & 0.1159 & 0.1258 & 0.1852 & 0.2064 & 0.2570 \\
\hline
\end{tabular}

The next step is the estimation of distance matrix $(Q)$ elements of NTMP alternatives from border approximate area matrix $(B)$.The distance of the alternative NTMPs from matrix $B$ is determined using Eq. (17) as the difference between the elements in weighted matrix $(V)$ and the values from the elements of matrix $B$, as exhibited in Table 14. For example, element $q_{11}$ is calculated as follows:

$$
q_{11}=v_{11}-b_{1}=0.2333-0.3706=-0.1372
$$

Table 14 Distance of NTMP alternatives from border approximation area (B)

\begin{tabular}{crrrrrrr}
\hline NTMP & \multicolumn{1}{c}{ TL } & \multicolumn{1}{c}{ SF } & \multicolumn{1}{c}{ SD } & \multicolumn{1}{c}{ T } & \multicolumn{1}{c}{ C } & \multicolumn{1}{c}{ MRR } & \multicolumn{1}{c}{ M } \\
\hline $\mathrm{A}_{1}$ & -0.1372 & 0.0785 & 0.0412 & 0.0218 & -0.0352 & -0.0158 & 0.0382 \\
$\mathrm{~A}_{2}$ & 0.0961 & 0.0868 & 0.0231 & 0.0218 & -0.0652 & 0.1412 & 0.0382 \\
$\mathrm{~A}_{3}$ & -0.0111 & -0.0375 & 0.0392 & -0.0520 & 0.0248 & -0.0193 & -0.1094 \\
$\mathrm{~A}_{4}$ & 0.0520 & -0.1204 & -0.0373 & 0.0180 & 0.0548 & -0.0326 & 0.0382 \\
$\mathrm{~A}_{5}$ & 0.0520 & 0.0454 & -0.0373 & 0.0105 & 0.0548 & -0.0326 & 0.0382 \\
\hline
\end{tabular}

The last step is the calculation of criteria function $\left(S_{i}\right)$ values for each NTMP alternative. The $S_{i}$ values of the alternative NTMPs along with their ranks are presented in Table 15. For example, $S_{i}$ value of $\mathrm{A}_{1}(\mathrm{AJM})$ is computed as below:

$$
S_{i}\left(A_{1}\right)=-0.1372+0.0785+0.0412+0.0218-0.0352-0.0158+0.0382=-0.0085
$$

The results of Table 15 imply that alternative $\mathrm{A}_{2}$ (USM) is ranked as the first one, and alternative $\mathrm{A}_{3}(\mathrm{CHM})$ as the worst and the least favorable NTMP. The results show that the rankings of the NTMPs are exactly the same as those derived by Yurdakul and Cogun [5] using a combined AHP-TOPSIS method, which leads to the confirmation that the proposed FARE-MABAC model can be an effective, efficient and simple method for solving complex NTMP selection problems.

Table 15 NTMPs with $S_{i}$ values and corresponding ranks

\begin{tabular}{crcc}
\hline NTMP & $S_{i}$ value & Rank & AHP-TOPSIS [5] \\
\hline $\mathrm{A}_{1}$ & -0.0085 & 3 & 3 \\
$\mathrm{~A}_{2}$ & 0.3421 & 1 & 1 \\
$\mathrm{~A}_{3}$ & -0.1653 & 5 & 5 \\
$\mathrm{~A}_{4}$ & -0.0272 & 4 & 4 \\
$\mathrm{~A}_{5}$ & 0.1310 & 2 & 2 \\
\hline
\end{tabular}




\section{CONCLUSIONS}

This paper presents a new FARE-MABAC model for NTMP selection problems in manufacturing domain. This combined application is based on an uncomplicated weight calculation tool which involves least amount of mathematical calculations, followed by a simple ranking methodology. The analytical results show that the ranking preorder produced by the FARE-MABAC approach exactly corroborate with those derived by the past researchers and that the proposed procedure is comprehensible to NTMP selection process under conflicting multi-criteria environment. The computations of the proposed approach are simple and explained in detail. It is apparent that the proposed FAREMABAC model is very easy-to-use in real-life engineering applications as it does not involve much expert opinion or qualitative process for criteria weight calculation. Also, it is expected to assists engineers and designers in making critical decisions during the selection of the best alternative in complex environment.

\section{REFERENCES}

1. Jain, V.K., 2005, Advanced Machining Processes, Allied Publishers Pvt. Limited, New Delhi.

2. Pandey, P.C., Shan, H.S., 1981, Modern Machining Processes, Tata McGraw-Hill Publishing Company Ltd., New Delhi.

3. Cogun, C., 1993, Computer-aided system for selection of nontraditional machining operations, Computer in Industry, 22(2), pp.169-179.

4. Cogun, C., 1994, Computer aided preliminary selection of non-traditional machining processes, International Journal of Machines Tools and Manufacture, 34(3), 315-326.

5. Yurdakul, M., Cogun, C., 2003, Development of a multi-attribute selection procedure for nontraditional machining processes, Proc. of the Institution of Mechanical Engineers, Journal of Engineering Manufacture, 217(7), pp. 993-1009.

6. Chakroborty, S., Dey, S., 2006, Design of an analytic-hierarchy-process-based expert system for nontraditional machining process selection, International Journal of Advanced Manufacturing Technology, 31(5-6), pp. 490-500.

7. Chakroborty, S., Dey, S., 2007, QFD-based expert system for non-traditional machining processes selection, Expert Systems with Applications, 32(4), pp. 1208-1217.

8. Das Chakladar, N., Chakraborty, S., 2008, A combined TOPSIS-AHP method based approach for nontraditional machining processes selection, Proc. of the Institution of Mechanical Engineers, Journal of Engineering Manufacture, 222(12), pp. 1613-1623.

9. Edison Chandrasselan, R., Jehadeesan, R., 2008, Web-based knowledge base system for selection of non-traditional machining processes, Malaysian Journal of Computer Science, 21(1), pp. 45-56.

10. Edison Chandrasselan, R., Jehadeesan, R., 2008, A knowledge base for non-traditional machining process selection, International Journal of Technology, Knowledge \& Society, 4(4), pp. 37-46.

11. Das Chakladar N., Das, R., Chakraborty, S., 2009, A digraph-based expert system for non-traditional machining processes selection, International Journal of Advanced Manufacturing Technology, 43(3-4), pp. 226-237.

12. Sadhu, A., Chakraborty, S., 2011, Non-traditional machining processes selection using data envelopment Analysis (DEA), Expert Systems with Applications, 38(7), pp. 8770-8781.

13. Das, S., Chakraborty, S., 2011, Selection of non-traditional machining processes using analytic Network process, Journal of Manufacturing Systems, 30(1), pp. 41-53.

14. Chakraborty, S., 2011, Applications of the MOORA method for decision making in manufacturing environment, International Journal of Advanced Manufacturing Technology, 54(9-12), pp. 1155-1166.

15. Temuçin, T., Tozan, H., Valíček, J., Harničárová., 2012, A fuzzy based decision support model for nontraditional machining process selection, Proc. of $2^{\text {nd }}$ International Conference on Manufacturing Engineering \& Management, Slovakia. pp. 170-175.

16. Karande, P., Chakraborty, S., 2012, Application of PROMETHEE-GAIA method for non-traditional machining processes selection, Management Science Letters, 2(6), pp. 2049-2060. 
17. Temucin, T., Tozan, H., Valicek, J., Harnicarova, M., 2013, A fuzzy based decision support model for non-traditional machining process selection, Technical Gazette, 20(5), pp. 787-793.

18. Choudhury, T., Das, P. P., Roy, M. K., Shivakoti, I., Ray, A., Pradhan, B. B., 2013, Selection of nontraditional machining process: A distance based approach, in Proceedings of Industrial Engineering and Engineering Management (IEEM), 2013 IEEE International Conference, pp. 852-856.

19. Prasad, K., Chakraborty, S., 2014, A decision-making model for non-traditional machining processes selection, Decision Science Letters, 3(4), pp. 467-478.

20. Temuçin, T., Tozan, H., Vayvay, Ö., Harničárová, M., Valíček, J., 2014, A fuzzy based decision model for nontraditional machining process selection, International Journal of Advanced Manufacturing Technology, 70(9-12), pp. 2275-2282.

21. Roy, M. K., Ray, A., Pradhan, B. B., 2014, Non-traditional machining process selection using integrated fuzzy AHP and QFD techniques: a customer perspective, Production \& Manufacturing Research, 2(1), pp. 530-549.

22. Madić, M., Radovanović, M., Petković, D, 2015, Non-conventional machining processes selection using multi-objective optimization on the basis of ratio analysis method, Journal of Engineering Science and Technology, (10)11, 1441-1452.

23. Khandekar, A. V., Chakraborty, S., 2016, Application of fuzzy axiomatic design principles for selection of non-traditional machining processes, International Journal of Advanced Manufacturing Technology, 83(14), pp. 529-543.

24. Boral, S., Chakraborty, S., 2016, A case-based reasoning approach for non-traditional machining processes selection. Advances in Production Engineering \& Management, 11(4,), pp. 311-323.

25. Roy, M. K., Ray, A., Pradhan, B. B., 2017, Non-traditional machining process selection-an integrated approach, International Journal for Quality Research, 11(1), pp. 71-94.

26. Herath, G., Prato, T., 2006, Using multi-criteria decision analysis in natural resource management, Ashgate Publishing Ltd.

27. Chakraborty S., Chatterjee, P., 2013, Selection of materials using multi-criteria decision-making methods with minimum data, Decision Science Letters, 2(3), pp. 135-148.

28. Fare, R., Grosskopf, S., Kirkley, J. E., Squires, D. Data Envelopment Analysis (DEA): A Framework for Assessing Capacity In Fisheries When Data are Limited, IIFET 2000 Proceedings.

29. Ali, A. I., Lerme, C. S., 1997, Comparative advantage and disadvantage in DEA, Annals of Operations Research, 73, pp. 215-232.

30. Abu-Assab, S., 2012, Integration of Preference Analysis Methods into QFD for Elderly People: A Focus on Elderly People, Springer Science \& Business Media.

31. Poel, I. V. D., 2007, Methodological problems in QFD and directions for future development, Research in Engineering Design, 18, pp. 21-36.

32. Sen, D. K., Datta, S., Patel, S. K., Mahapatra, S. S., 2015, Multi-criteria decision making towards selection of industrial robot Exploration of PROMETHEE II method, Benchmarking: An International Journal, 22(3), pp. $465-487$.

33. Gineviciu, R., 2011, A new determining method for the criteria weights in multicriteria evaluation, International Journal of Information Technology \& Decision Making, 10(6), pp. 1067-1095.

34. Yazdani, M., 2015, New approach to select materials using MADM tools, International Journal of Business and Systems Research, In press, pp.1-18.

35. Pitchipoo. P., Vincent D.S., Rajini, N., Rajakarunakaran S., 2014, COPRAS Decision Model to Optimize Blind Spot in Heavy Vehicles: A Comparative Perspective, Procedia Engineering. 97, pp. 1049 -1059.

36. Pamučar, D., Ćirovic, G., 2015, The selection of transport and handling resources in logistics centers using Multi-Attributive Border Approximation area Comparison (MABAC), Expert Systems with Applications, 42, pp. 3016-3028.

37. Gigović, L., Pamučar, D., Božanić, D., Ljubojević, S., 2017, Application of the GIS-DANP-MABAC multicriteria model for selecting the location of wind farms: A case study of Vojvodina, Serbia, Renewable Energy, 103, pp. 501-521.

38. Pamučar, D., Mihajlović, M., Obradović, R., Atanasković, P., 2017, Novel approach to group multicriteria decision making based on interval rough numbers: Hybrid DEMATEL-ANP-MAIRCA model, Expert Systems with Applications, 88, pp. 58-80.

39. Pamučar, D., Petrović, I., Ćirović, G., 2018, Modification of the Best-Worst and MABAC methods: A novel approach based on interval-valued fuzzy-rough numbers, Expert Systems with Applications, 91, pp. 89-106. 